\title{
PERFORMANCE OPTIMIZATION OF RADIAL FLOW CENTRIFUGAL PUMP IMPELLER USING CFD
}

\author{
Karun Mendiratta ${ }^{1}$, Krishna Kumar Yadav ${ }^{2}$ V K Gahlot ${ }^{3}$ \\ ${ }^{I}$ Assistant Professor, Department of Mechanical Engineering, NIET, Greater Noida, UP, India \\ ${ }^{2}$ Assistant Professor, Department of Mechanical Engineering, NIET, Greater Noida, UP, India \\ ${ }^{3}$ Professor, Department of Civil Engineering, MANIT, Bhopal, MP, India
}

\begin{abstract}
This work aims to analyze the hydraulic performance and characteristics of a centrifugal pump using ANSYS CFX (ver.14.0). A centrifugal radial flow pump has been designed to deliver $0.0074 \mathrm{~m}^{3} / \mathrm{s}$ of water with a head of $30 \mathrm{~m}$ running at a speed of 2870 rpm. The pump unit has been modeled using PTC Creo (ver. 2.0). Computation fluid dynamics (CFD) has been used to analyze the flow characteristics. The performance of the pump was first determined using the existing thickness of blade and then, the thickness of blades has been varied to analyze the pump's performance. The results show that for an initial 10mm blade thickness, the efficiency of the pump was $82.98 \%$. However, the efficiency of pump increased by $1.87 \%$ for the optimized 5 mm blade.
\end{abstract}

Keywords: Computational Fluid Dynamics (CFD) Analysis, Radial Flow Pump, Blade thickness, Overall Efficiency.

\section{INTRODUCTION}

Centrifugal pumps have a snail shaped casing which can be identified easily and have its application all around in our houses and as well as industries. Radial flow centrifugal pumps are used when moderate head and discharge is required. The fluid enters axially through impeller at the eye, acquires tangential and radial velocity as a result of the momentum transfer, and leaves the impeller radially outwards into the volute, after gaining speed and pressure. Based on impeller geometry, centrifugal pumps are classified as; 1) Backward inclined blades, 2) Straight or Radial blades, and 3) Forward inclined blades. Backward inclined blades are the most common ones and yield highest efficiency of others. Radial blade type (straight blade) has simple geometry and produces greatest pressure rise over a wide range of volume flow rates.

In order to enhance the pump performance, designers are consistently working on to provide the machines that are more efficient, cheap, and reliable. Gahlot \& Nyiri [1] observed that in doing so, it is of utmost importance to define the shape and size of impeller vanes. A shorter passage length might result in flow separation and eddy formation. However, a longer passage results in higher frictional losses. Several researchers have performed numerical modeling, simulation, and analysis of 3-D turbulent flow in centrifugal pump impellers using RANS equations. It has been observed that the hydraulic efficiency increases by optimizing the impeller geometry within typical errors ranging below $10 \%$ [2, 3]. Jude \& Homentcovschi [4], used conformal mapping and boundary element technique in order to study the flow through a 2-D centrifugal impeller using equiangular blades of arbitrary geometry [4]. With only minute differences, the result proved to be a fair match with the results previously obtained for logarithmic spiral blades.
Oyelami et al. [5] observed that the amount of energy imparted to the liquid is proportional to the velocity at the edge or tip of the vane of impeller. Different vane profiles were used to evaluate the performance of a designed blower. In addition, it was concluded that the pump performance was also influenced by the fact that the impeller is open-type or closed-type. Closed impeller having backward curved vanes showed the best performance or efficiency with respect to output speed and flow rate. Jain et al. [6] investigated the methods to optimize the geometric and operational parameters of a centrifugal pump which runs in turbine mode. With varying rotational speed between 900 rpm to $1500 \mathrm{rpm}$, and with no, $10 \%$ trimming, and $20 \%$ trimming of impellers, the performance increased at lower speeds rather than at rated speed. Blade rounding also led to 3-4\% efficiency rise. Pandit et al. [7] studied the effect of trimming of impeller diameter in a radial-submersible pump. With $10 \%$ reduction, the capacity of the original impeller changed. Thus, this method could be opted as useful correction technique for oversized impellers, without the need of building new ones.

As observed by Somashekar \& Purushothama [8], a cavitation phenomenon has a strong relation with the Design, operation and refurbishment of centrifugal pumps. Cavitation takes place near the suction surface, and expands towards the trailing edge. It has been seen that, the blade width (b) greatly affects the pump performance. As b increases, leakage increases but, efficiency and head of the pump decrease [9].

CFD is a widely used effective tool by many researchers to carry out different studies and investigations on the centrifugal pumps. CFD analysis is better when compared with trial and error methods [10]. Steady state 3-D NavierStokes equations combined with the k-epsilon turbulence 
model have been used widely. Ajith \& Isaac [11] investigated the flow through centrifugal pump impeller with forward and backward curved vanes using the ANSYS. The backward curved vanes were found to have better performance than its counterpart. CFD has also been used to study, analyze and predict various parameters affecting impeller performance of a radial flow-type centrifugal pump. Studies like of Kaewnai et al. [12], revealed that the surface roughness has high impact on the pump losses, i.e. as surface roughness increases, loss coefficient too increases.

A dearth in research papers explaining efficiently the radial flow type vane profile design procedures, Designers these days have to reverse engineer the vanes which are popularly available in the market. This paper is thus an effort to provide a step by step guidance to design a radial type vane profile using Double Arc method. This research aims to analyze the effect of blade thickness ( $t$ ) on the performance of radial flow pump, and to find out the optimal value that could enhance the overall efficiency of the pump.

\section{PUMP SPECIFICATIONS}

\subsection{Impeller Geometry}

The performance of a radial flow pump is highly dependent on its impeller geometry. In the present work, a pump has been designed with its specifications shown in Table-1., and effect of blade thickness ( $t$ ) on its performance has been analyzed. Detailed study has been performed on the geometric features of the impeller. Model of the designed pump and impeller is shown in Fig.1 and Fig.2.

Table-1: Design specification of pump

\begin{tabular}{|c|c|}
\hline Design & Specifications \\
\hline Flow rate $\left(\mathrm{m}^{3} / \mathrm{s}\right)$ & 0.0074 \\
\hline Head $(\mathrm{m})$ & 30 \\
\hline Rotating speed $(\mathrm{rpm})$ & 2870 \\
\hline
\end{tabular}

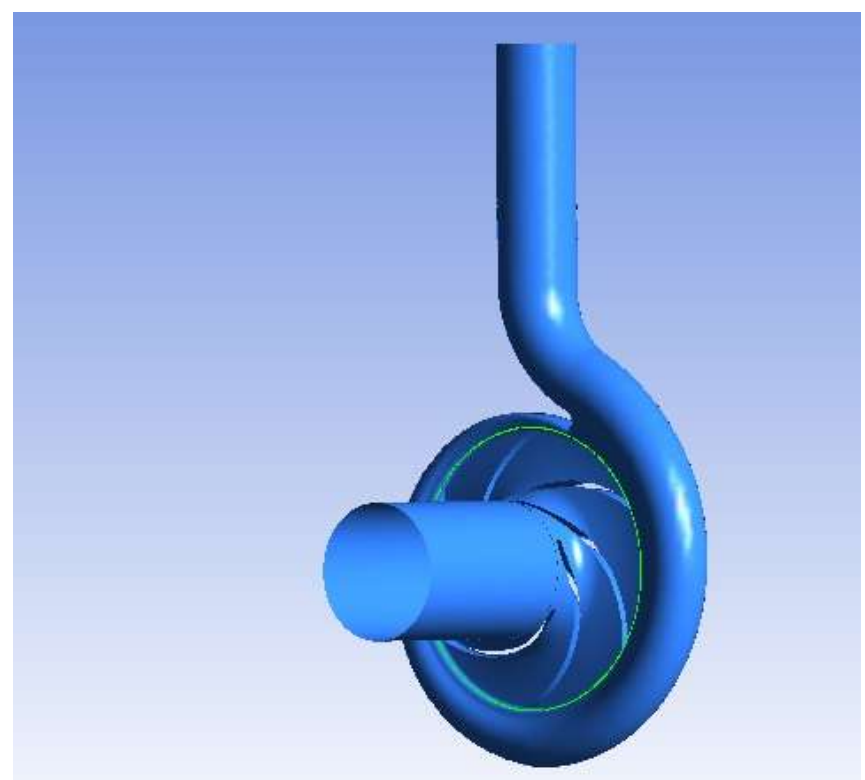

Fig-1: Model of Pump
In order to investigate the effects of these geometric features on the pump flow and impeller performance, parameterization has been done by reducing the number of controlling geometric variables as shown in Table- 2 .

Table-2: Geometrical features of the impeller

\begin{tabular}{|c|c|}
\hline Parameter & Size \\
\hline Inlet diameter $\left(\mathrm{d}_{1}\right)$ & $66 \mathrm{~mm}$ \\
\hline Outlet diameter $\left(\mathrm{d}_{2}\right)$ & $172 \mathrm{~mm}$ \\
\hline Vane inlet angle $\left(\beta_{1}\right)$ & $23^{\circ}$ \\
\hline Vane outlet angle $\left(\beta_{2}\right)$ & $29^{\circ}$ \\
\hline Number of blades $(\mathrm{z})$ & 6 \\
\hline Blade thickness $(\mathrm{t})$ & $10 \mathrm{~mm}$ \\
\hline Shaft diameter $\left(\mathrm{d}_{\mathrm{sh}}\right)$ & $25 \mathrm{~mm}$ \\
\hline Blade inlet height $(\mathrm{b} 1)$ & $15 \mathrm{~mm}$ \\
\hline Blade outlet height $(\mathrm{b} 2)$ & $6 \mathrm{~mm}$ \\
\hline
\end{tabular}

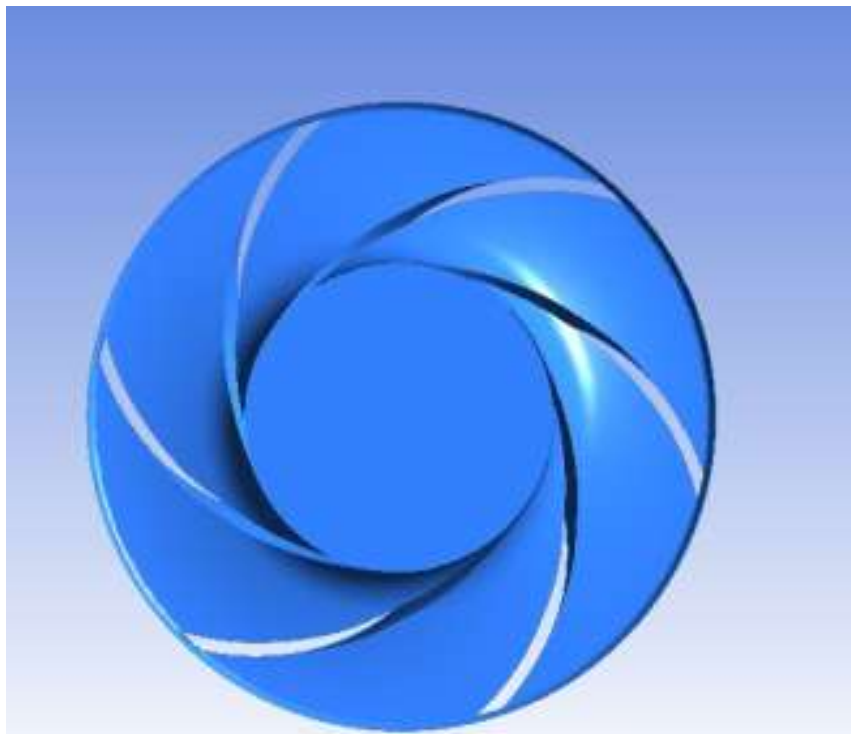

Fig-2: Model of Pump Impeller

\section{METHOD FOR CONSTRUCTING THE VANE} SHAPE

\subsection{Circular Arc Method}

An impeller is usually divided into number of concentric rings between radius $R_{1}$ and $R_{2}$ in a random manner. Vane profile thus can be defined by using either one arc or two arcs of the circle. The double arc method gives better results as compared to the single arc method.

Vane profile in double arc method is constructed by joining arcs of the two circles, drawn through points $\mathrm{A}$ and $\mathrm{B}$. The circle is divided into ' $\mathrm{Z}$ ' equal parts which pass through the inlet edge of the blades of diameter. $\mathrm{C}_{1} \mathrm{P}_{1}, \mathrm{C}_{2} \mathrm{P}_{2}$ are the tangents drawn from the division points $C_{1}, C_{2}, C_{3}$, etc touching the radius of circle, $\delta=\mathrm{d}_{1} \operatorname{Sin} \beta_{1}$. From the points of intersection $\left(\mathrm{P}_{1}, \mathrm{P}_{2}\right.$ etc. $)$, arcs having radius $\rho_{1}=\mathrm{P}_{1} \mathrm{C}_{1}=$ 
$\mathrm{P}_{2} \mathrm{C}_{2}$ and so on, are drawn. Each arc here forms the inlet part of vane and an approximate portion of the involute curve.

Line OE is further extended to meet the circle of radius $R_{2}$ at point $\mathrm{B}$. Another line $\mathrm{BG}$ is drawn at an angle of $\beta_{2}$ to line $\mathrm{OB}$. Where, the remaining part of the vane is formed by a smooth curve or another circular arc with centre G.

The radius of an arc of the circle is determined by;

$$
\rho_{2}=\frac{R 2^{2}-R 1^{2}}{2\left(R_{2} \operatorname{Cos} \beta_{2-} R_{1} \operatorname{Cos} \beta_{1}\right)}
$$

Where; radius $\mathrm{R}_{\mathrm{F}}$ is equal to $\mathrm{OF}$ and, angle $\beta_{1}$ is angle EFO. If the blade thickness is kept constant, the drawn profile acts as the centre line for the vane.

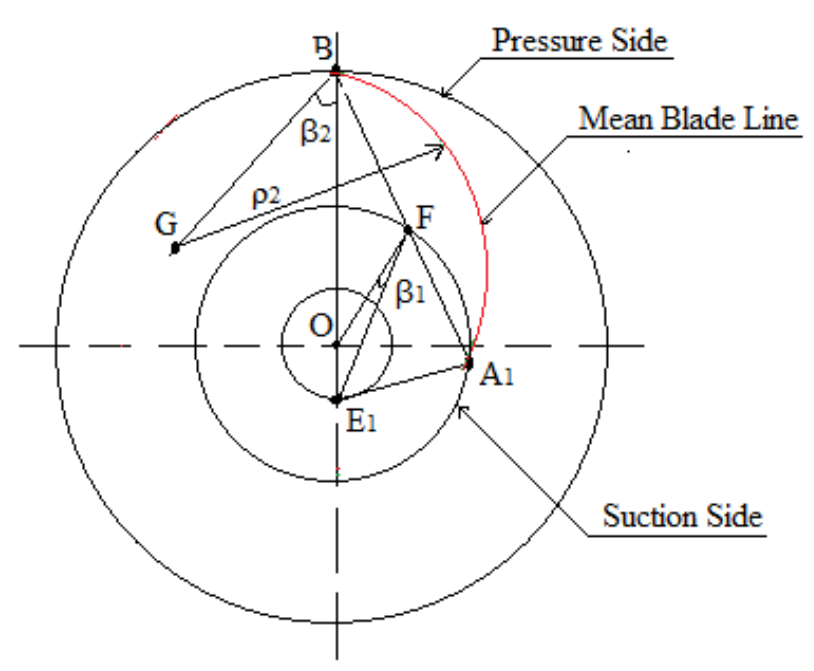

Fig-3: Double Arc method

\section{METHODS TO CALCULATE VOLUTE}

\section{CASING}

\subsection{Principle of Constant Moment of Momentum}

According to this principle, the moment of momentum remains constant at different sections, which can be calculated by;

$$
\mathrm{M}=\mathrm{Cu} \mathrm{r}=\mathrm{Cu}_{1} \mathrm{r}=\text { constant }
$$

\subsection{Principle of Constant Mean Velocity}

Discharge at any section of the volute is given by;

$$
Q_{\varnothing}=\frac{\mathrm{Q} * \emptyset^{\circ}}{360^{\circ}}
$$

And, the Area of volute at any section, by;

$$
A_{\varnothing}=\frac{Q_{\emptyset}}{\mathrm{C}_{3}}=\frac{\mathrm{Q} \times \emptyset^{\circ}}{360^{\circ} \times \mathrm{C}_{3}}
$$

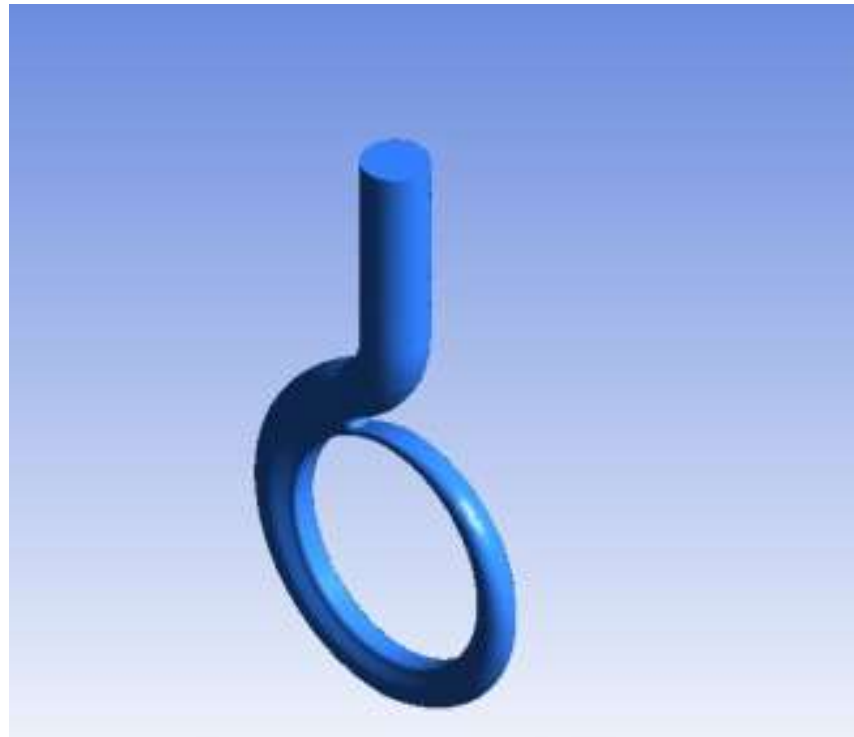

Fig-4: Model of Casing

\section{MESHING OF PUMP ASSEMBLY}

ANSYS was used to develop the final mesh of the pump assembly, as shown in Fig.5. Total number of elements and nodes are given in Table-3.

Table-3: Mesh information of pump assembly

\begin{tabular}{|c|c|c|c|c|}
\hline $\begin{array}{c}\text { Total } \\
\text { elements }\end{array}$ & $\begin{array}{c}\text { Total } \\
\text { nodes }\end{array}$ & TRI_3 & TETRA_4 & LINE_2 \\
\hline 5851460 & 1170596 & 235102 & 5611060 & 8180 \\
\hline
\end{tabular}

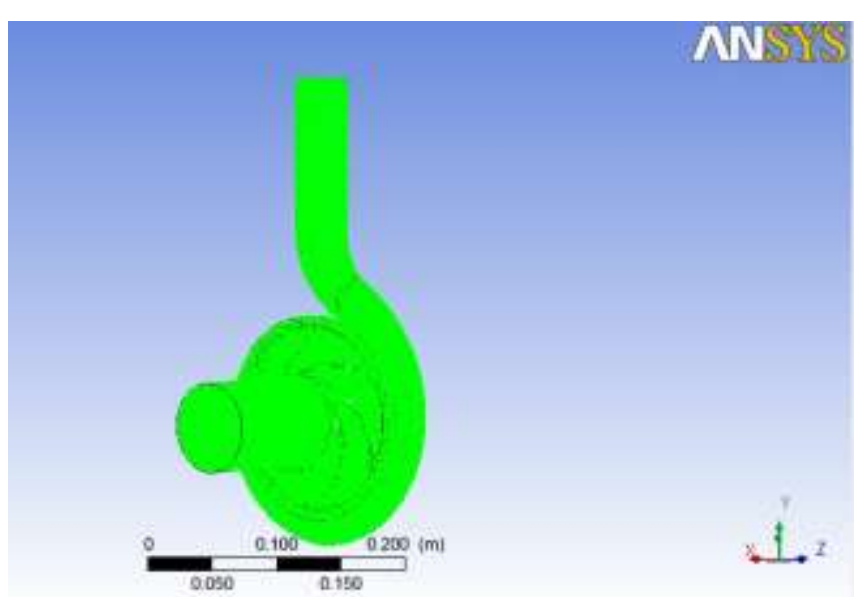

Fig-5: Meshing of designed pump.

\section{BOUNDARY CONDITIONS}

The numerical computation assumes a steady-state condition with the following boundary conditions. Radial flow pump impeller domain is a rotating frame of reference with working fluid as water at $25^{\circ} \mathrm{C}$, rotational speed of 2870 $\mathrm{rpm}, 1 \mathrm{~atm}$. pressure at inlet, and $0.0074 \mathrm{~m}^{3} / \mathrm{s}$ of discharge at the outlet. Turbulence intensity of $5 \%$ is considered in $\mathrm{k}-\varepsilon$ model. 


\subsection{Velocity Stream Contour}

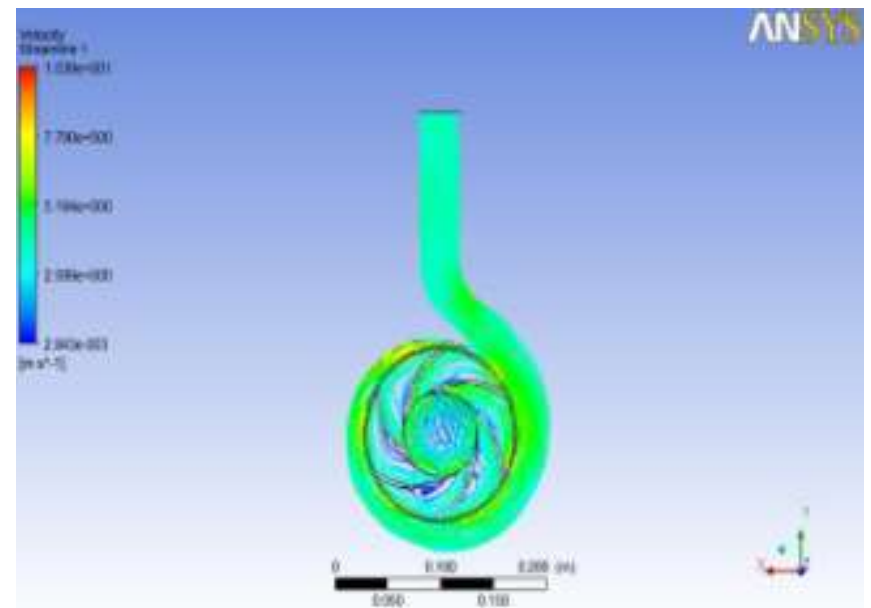

Fig-6: Velocity Stream Contour

\subsection{Pressure Contour}

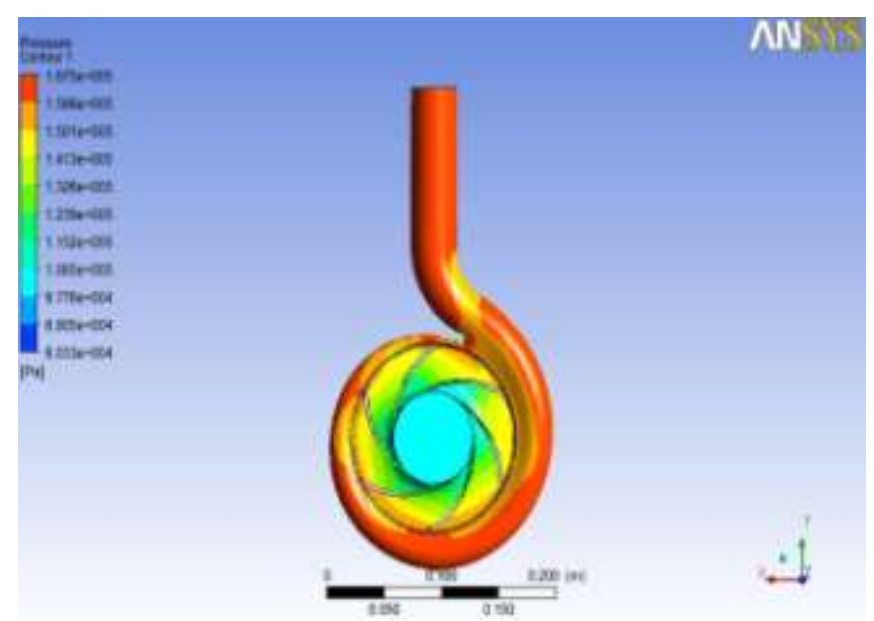

Fig-7: Pressure Contour

\section{RESULTS}

Inlet power (IP) can be calculated as;

$$
\begin{gathered}
\Rightarrow 2 \pi \mathrm{NT} / 60 * 1000 \\
\Rightarrow\left(2 \pi^{*} 2870 * 19.63\right) / 60 * 1000 \\
\Rightarrow 5.899 \mathrm{KW}
\end{gathered}
$$

And, Outlet power (OP) can be calculated as;

$$
\begin{gathered}
\Rightarrow(\mathrm{P} 0-\mathrm{Pi}) * \mathrm{Q} / 1000 \\
\Rightarrow(680522.42-18900.8) * 0.0074 / 1000 \\
\Rightarrow 4.896 \mathrm{KW}
\end{gathered}
$$

So, Overall efficiency $=($ Outlet power $/$ Input power $)$

$$
\begin{gathered}
\Rightarrow 4.895 / 5.899 \\
\Rightarrow 0.8299
\end{gathered}
$$

\section{OPTIMIZATION OF RESULTS}

\subsection{Optimization of Number of Blades}

Table-4: Variation in blade thickness

\begin{tabular}{|c|c|c|}
\hline Impeller & Blade Thickness, $\mathbf{~ ( m m )}$ & Efficiency $(\%)$ \\
\hline Impeller 1 & 10 & 82.99 \\
\hline Impeller 2 & 9 & 83.22 \\
\hline Impeller 3 & 8 & 83.52 \\
\hline Impeller 4 & 7 & 83.75 \\
\hline Impeller 5 & 6 & 84.13 \\
\hline Impeller 6 & 5 & 84.57 \\
\hline
\end{tabular}

\subsection{Results from Optimization}

Table-5: Impeller efficiency

\begin{tabular}{|c|c|c|c|}
\hline Impeller & $\begin{array}{c}\text { Inlet power } \\
(\mathbf{K W})\end{array}$ & $\begin{array}{c}\text { Outlet power } \\
(\mathbf{K W})\end{array}$ & Efficiency (\%) \\
\hline Impeller 1 & 5.899 & 4.896 & 82.99 \\
\hline Impeller 2 & 5.657 & 4.708 & 83.22 \\
\hline Impeller 3 & 5.746 & 4.799 & 83.52 \\
\hline Impeller 4 & 5.921 & 4.959 & 83.75 \\
\hline Impeller 5 & 6.043 & 5.084 & 84.13 \\
\hline Impeller 6 & 6.035 & 5.104 & 84.57 \\
\hline
\end{tabular}

\subsection{Efficiency Vs Mass Flow Rate}

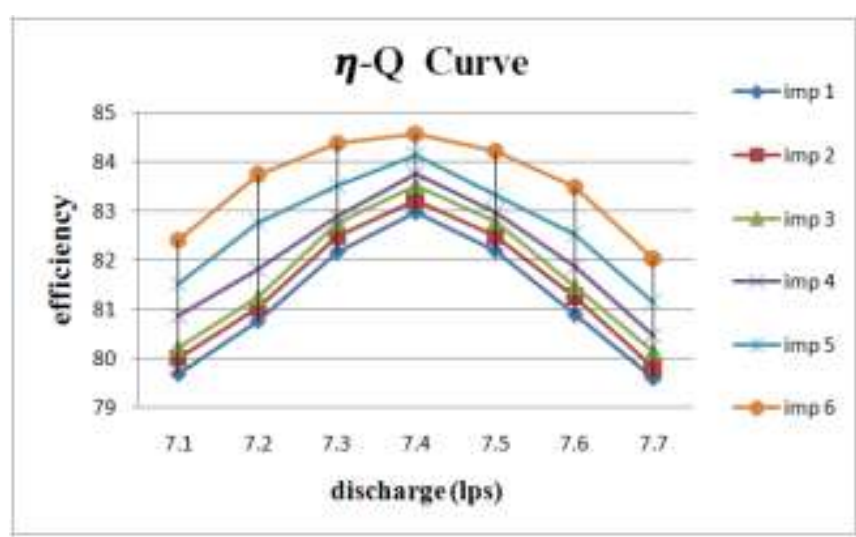

Fig-8: Efficiency Vs Mass Flow Rate

\section{CONCLUSION}

Based on the detailed design and extensive CFD analysis of radial flow impeller, it can be concluded that thickness of impeller blade has a significant effect on the performance of radial flow pump. The Optimum efficiency was obtained for Impeller 6 having blade thickness of $5 \mathrm{~mm}$ (opt.). It has been observed that the overall efficiency of pump at optimum value increases by $1.87 \%$. 


\section{REFERENCES}

[1]. Gahlot, V. K., \& Nyiri, A. (1993). "Impeller Pumps, Theory and Design", M.A.C.T, Bhopal, Madhya Pradesh, India.

[2]. Anagnostopoulos, J. S. (2006). "CFD Analysis and Design Effects in a Radial Pump Impeller", WSEAS Transactions on Fluid Mechanics, 7(1), pp. 763-770.

[3]. Shah, S. R., Jain, S. V., Patel, R. N., \& Lakhera, V. J. (2013). "CFD for centrifugal pumps: a review of the state of the art", Procedia Engineering, 51, pp. 715 - 720.

[4]. Jude, L., \& Homentcovschi, D. (1998). "Numerical analysis of the inviscid incompressible Flow in two dimensional radial-Flow pump impellers", Engineering Analysis with Boundary Elements, 22, pp. 271-279.

[5]. Oyelami, A.T., Adejuyigbe, S.B., Waheed, M.A., Ogunkoya, A.K., \& Iliya, D. (2012). "Analysis of RadialFlow Impellers of Different Configurations", The Pacific Journal of Science and Technology, 13(1), pp. 24-33.

[6]. Jain, S. V., Swarnkar, A., Motwani, K. H., \& Patel, R. N. (2015). "Effects of impeller diameter and rotational speed on performance of pump running in turbine mode", Energy Conversion and Management, 89, pp. 808-824.

[7]. Pandit, H. C., Gundale, V.A., \& Patankar, R. C. (2016). "The Effect of Trimming the Diameter of a Radial type Submersible Pump Impeller", Imperial Journal of Interdisciplinary Research, 2(5), pp. 1344-1349.

[8]. Somashekar, D., \& Purushothama, H. R. (2012), "Numerical Simulation of Cavitation Inception on Radial Flow Pump", IOSR Journal of Mechanical and Civil Engineering, 1(5), pp. 21-26.

[9]. Chen, Z., Gu, Y., \& Fan, T. (2016), "Effect of sealing ring clearance on pump performance", WORLD PUMPS, March 2016, pp. 38-41.

[10]. Ramasamy, H., \& Prakash, P. (2015). "CFD Approach in the Design of Radial Flow Centrifugal Pump Impeller", International Journal of Scientific Engineering and Applied Science, 1(5), pp. 500-503.

[11]. Ajith, M. S., \& Issac, J. M. (2015). "Design and Analysis of Centrifugal Pump Impeller using ANSYS Fluent", International Journal of Science, Engineering and Technology Research, 4(10), pp. 3640-3643.

[12]. Kaewnai, S., Chamaoot, M., \& Wongwises, S. (2009). "Predicting performance of radial flow type impeller of centrifugal pump using CFD", Journal of Mechanical Science and Technology, 23, pp. 1620-1627.

\section{BIOGRAPHIES}

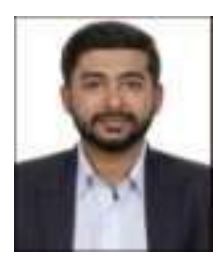

Karun Mendiratta, Assistant Professor, Mechanical Department, NIET, Greater Noida

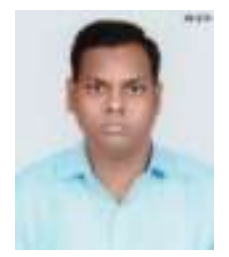

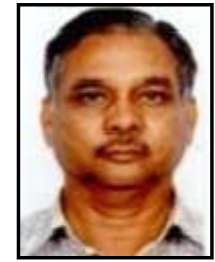

V. K. Gahlot, Professor, Civil Department, MANIT, Bhopal 